\title{
Order Effects \\ And The Audit Materiality Revision Choice
}

Charles A. Brown, Penn State Erie, The Behrend College, USA

\begin{abstract}
Prior literature has examined order effects in a variety of auditor decision-making judgments. This study expands the order effect literature by examining the impact of qualitative information on auditors' willingness to revise materiality thresholds subsequent to the completion of audit fieldwork. If financial reporting risk (the risk of failing to report misstatements appropriately) is present in an audit engagement, auditors may choose to revise their materiality thresholds upward, causing seemingly material misstatements to become quantitatively immaterial. Consequently, financial reporting risk is assumed away and auditors do not appear negligent in their professional responsibilities. The results show that auditors are in fact willing to revise their materiality judgments given qualitative information and that different levels of inherent risk present in the audit environment also affects these revisions. In addition, the order in which the qualitative information is presented to auditors has a significant effect on the materiality judgment revisions. More specifically, significant recency order-effects are identified in the leastexperienced (newly hired staff) and most-experienced (managers and partners) auditor groups, given high and low levels of inherent risk. Finally, the most-experienced auditor group shows the most pronounced order-effect biases.
\end{abstract}

Keywords: Order Effects, Materiality, Auditor Judgment, Belief Revision

Data Availability: Contact the author

\section{INTRODUCTION}

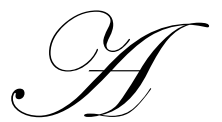

nchored in psychology, belief revision concerns how people update beliefs across time and its sequential nature. However, as noted by Anderson (1981) "basic to the study of serial integration (of audit information) is the problem of order effects" (emphasis added). Order effects, whether recency or primacy, occur when two or more groups of individuals express different final judgments after examining the same information presented in different orders. A significant amount of accounting research indicates that auditors are susceptible to recency bias or the order effect that occurs when information processed later in a sequence has greater influence over the final judgment. However, none of these studies examine the impact of order effects on the likelihood of revising materiality thresholds.

Studying potential order effects on auditor materiality judgments is important given the recent corporate frauds and the elimination of "Big 5" accounting firm Arthur Anderson during the last decade. Waste Management, Sunbeam, and Enron (among others) are adjoined by one common thread - the misapplication of materiality, which resulted in Anderson's collapse. In all three cases, the auditors identified improper accounting but, after persuasion by management, allowed it to continue. And in all three cases, the defense of the auditor was that the transactions were immaterial. In response to the corporate scandals and mismanagement, Congress enacted the Sarbanes-Oxley Act of 2002, which takes away the self-regulation powers of the auditing profession and heightens corporate management responsibilities. However, whether the profession or Congress is governing the independent auditing function, two facts remain clear; underlying the application of generally accepted auditing standards are auditor judgment and the concept of materiality. 
During the past fifty years, a tremendous amount of research has explored the concept of materiality and how it should be applied in accounting and auditing situations. However, since the professional guidance has yet to provide specific quantitative guidance regarding materiality, much of the prior research has focused on developing appropriate materiality thresholds. Prior research (e.g. see Patillo 1976; Holstrom and Messier 1982; Slipp 1983) has primarily shown that a misstatement is material if it is approximately five to ten percent of operating income, which has become the materiality "rule of thumb." However, the Auditing Standards Board also recognizes in Statement on Auditing Standards No. 47, "Audit Risk and Materiality in Conducting an Audit" (SAS No. 47) the importance of both quantitative and qualitative information on auditor materiality judgments by noting "that materiality judgments are made in light of surrounding circumstances and necessarily involve both quantitative and qualitative considerations (emphasis added) [AICPA, 2001, AU§312.10]. Although SAS No. 47 documents the importance of qualitative items and their affect on materiality, few studies examine whether or not these items are in fact important to auditor materiality judgments. ${ }^{1}$ However, because of the current auditing environment and the release of Staff Accounting Bulletin (SAB) No. 99 - Materiality by the Securities and Exchange Commission (SEC 1999), more research focusing on the impact of qualitative information on auditor materiality judgments is warranted.

The purpose of this study focuses on the qualitative aspects of materiality and how qualitative information, or factors, affects the materiality judgment decisions made by auditors. Specifically, this study examines empirically the impact of qualitative information on auditors' willingness to revise materiality judgments subsequent to the completion of audit fieldwork. As discussed in Wright and Wright (1997), auditors may consider revising planning materiality when evaluating audit results due to the detection of audit errors. They note that if "financial reporting risk $^{2}$ is present on an engagement, auditors may revise planning materiality levels ex post so as to waive adjustments advantageous to a client and not appear negligent of professional responsibilities. That is, financial reporting risk can be assumed away" (p. 21). It is this potential ex post revision that is examined here and whether the presentation order of the qualitative information influences the revision decision.

The remainder of this paper is organized as follows. A review of the relevant literature is presented including the hypotheses developed. The research methodology and experimental instrument is then introduced. Finally, the results are presented along with a discussion on the major findings and implications along with suggestions for future research.

\section{BACKGROUND AND HYPOTHESES DEVELOPMENT}

Prior research has documented a lack of consistency in applying the concept of materiality for both auditors and accountants. Some critics believe this is due mainly to the lack of formal quantitative and qualitative guidance. Others believe that formal guidance would incorrectly eliminate the judgment process needed to make a proper materiality assessment. In general, the current professional guidance states that the auditor's consideration of materiality is a matter of professional judgment [AICPA 2001, \$132.10]. In response to the lack of specific guidance for applying materiality in practice, a tremendous amount of research has attempted to identify appropriate materiality thresholds (e.g. see Holstrom and Messier 1982; Pany and Wheeler 1989; Wheeler et al. 1993; Chewning et al. 1989 and 1998; Waters and Tiller 1997). In general, most research has shown that the primary factor for determining whether a misstatement is material is its affect on net income and that a misstatement of five to ten percent of income is deemed to be material to the financial statements.

The SEC issued SAB No. 99 - Materiality to reiterate the importance of quantitative and qualitative factors in making materiality judgments. The SEC's primary reason for issuing the SAB is due to its concern that companies are managing earnings so as to not miss analysts' earnings projections. A few studies have attempted to identify qualitative factors that auditors consider while making materiality judgments. The most common qualitative factor identified is a misstatement's affect on an earnings trend (Boatsman and Robertson 1974;

\footnotetext{
${ }^{1}$ See Marsh (1997), Steinbart (1987), or Krogstad et al. (1984) for examples of studies that have specifically considered or attempted to identify qualitative factors that affect auditor materiality judgments.

${ }^{2}$ Financial reporting risk is the risk of failing to appropriately report detected misstatements.
} 
Moriarity and Barron 1979; Messier 1983). ${ }^{3}$ Other qualitative factors identified include the risk of the audited company (Boatsman and Robertson 1974; Krogstad et al. 1984), the context of the circumstances surrounding the misstatement (Jennings et al. 1987; Friedberg et al. 1989), and competitive pricing and client pressure within the auditing industry (Walker 1999; Braun 2000).

The materiality research is extensive pertaining to quantitative thresholds, and although some studies have considered qualitative factors in making materiality judgments, prior literature has not addressed whether qualitative information (or factors) will cause auditors to revise these materiality judgments. As discussed above, Wright and Wright (1997) posit that auditors may consider revising planning materiality ex post when evaluating audit results due to the detection of audit errors. If financial reporting risk is present on an engagement, auditors may consider an ex post materiality revision to assume away this risk. It is the likelihood of this revision that is examined here, not its appropriateness. The latter is left for future research. Therefore, because of this gap in the extant literature, and the SEC's concerns, this study examines empirically the impact of qualitative information on auditors' willingness to revise materiality judgments subsequent to the completion of audit fieldwork.

A key issue to the study of belief revision is the problem of order effects. Hogarth and Einhorn (1992) introduced the Belief-Adjustment Model, which allows researchers to study order effect phenomena. Most of the audit research that has used this model shows that auditor judgments are susceptible to recency effects. Recency effects have been documented in a variety of auditor judgment tasks including payroll decisions and accounts receivable, internal control situations (Ashton and Ashton 1988), situations involving the overstatements of assets or the understatement of liabilities (Tubbs et al. 1990), going concern situations (Asare 1992; Messier 1992, Arnold et al. 2000, Ashton and Kennedy 2002, Favere-Marchesi 2006), inventory write-down situations (Reckers and Shultz 1993; Johnson 1995), and assessing audit reports in loan rating decisions (Guiral-Contreras et al. 2007). Studies in management accounting (Dillard et al. 1991), taxation (Pei et al. 1992a), government auditing (Pei et al. 1992b), and experimental asset markets (Tuttle et al. 1997) have also confirmed the recency effect predictions of the model. However, none of these studies examined the likelihood of revising materiality thresholds.

Anderson and Maletta (1999) examined whether inherent risk affects the auditor belief revision process and whether it causes a primacy effect. Psychology research shows that primacy is a function of diminishing cognitive effort and that risk drives cognitive effort (Anderson 1981; Hendrick and Costantini 1970; Anderson and Hubert 1963). Using an experimental task involving the sales/receivables area, Anderson and Maletta (1999) found that auditors were susceptible to primacy effects and that the effects were caused by auditors' failure to integrate late positive (confirming) information into their judgments in low inherent risk conditions. In the high inherent risk condition, primacy effects were not present.

Using a step-by-step (SbS) processing mode this study requires auditors to provide likelihood judgments on revising their materiality threshold after evaluating mixed (confirming and disconfirming) evidence. Arnold et al. (2000) suggest that due to the nature of the auditing environment auditors are not likely to use a pure SbS or EoS (end-of-sequence) processing mode. Considering the complexity of the profession, it is likely that an auditor will employ the SbS processing mode more often than not because "staff and senior level professionals often provide managers and partners periodic written or oral summaries based on information gathered up to a given point in time. Hence, staff and senior professionals are forced to evaluate blocks of information periodically to develop tentative conclusions and managers/partners receive these periodic summaries of information and similarly revise their conclusions based on blocks of information" (pg. 6). In the SbS processing-mode setting the Belief-Adjustment Model predicts recency whether a task is simple or complex. In practice, auditors must evaluate and make judgments with respect to large quantities of information, integrate this information, and then make an overall judgment, deciding whether or not the financial statements are free of material misstatements. Since this study examines an auditor judgment task near the end of the engagement, it is deemed to be a complex task due to the high information load and the timing of the judgments.

\footnotetext{
${ }^{3}$ Prior research has considered a misstatement's affect on an earnings trend as both a quantitative factor as well as a qualitative factor in making materiality judgments. To be consistent with SAB No. 99, this study considers a misstatement's affect on an earnings trend as a qualitative factor.
} 
In summary, a number of auditing studies have examined and confirmed the order effect predictions of the Belief Adjustment Model, primarily recency effects. Most of these studies have examined audit scenarios that were high in risk. Anderson and Maletta (1999) controlled for the effects of risk in the judgment process and found that auditors were susceptible to primacy effects when negative evidence preceded positive evidence in a low risk setting. However, prior research has not addressed whether the order of qualitative information affects auditors' willingness to revise their initial materiality threshold subsequent to the completion of audit fieldwork and whether inherent risk plays a significant role in the materiality judgment revision process. Therefore, the following three hypotheses are proposed:

H1: The initial likelihood judgments (the anchor judgment) of revising the initial materiality threshold in the low inherent risk audit environment will be greater than those in the high inherent risk audit environment.

H2: The decision to revise the initial materiality threshold subsequent to the completion of fieldwork is a function of the interaction between the presentation order of information and the level of inherent risk present in the audit environment.

H3: In the low (high) inherent risk audit environment, auditors' revised materiality likelihood judgments are expected to result in a primacy (recency) effect.

A number of studies have attempted to identify mitigating factors that alleviate the order effect bias. These studies have identified auditor experience (Messier and Tubbs 1994; Trotman and Wright 1996), task complexity (Trotman and Wright 1996; Monroe and Ng 2000), accountability/documentation (Kennedy 1993; Cushing and Ahlawat 1996), group decision making (Ahlawat 1999; Hunton 2001), and self-review (Ashton and Kennedy 2002) as the primary factors that help to mitigate order effects, specifically recency. However, other studies have shown that experience does not mitigate but accentuates recency effects (Krull et al. 1993; Arnold et al. 2000). For complex tasks that require substantial information load and processing, the research shows that order effects are not mitigated by experience. None of the previous research has examined whether experience mitigates order effects in making materiality judgments.

This study utilizes auditors from all experience levels to test whether qualitative factors impact materiality judgments. The participants are grouped into three experience levels: least experienced (staff and newly appointed seniors), experienced ("seasoned" seniors and audit supervisors), and most experienced (managers and partners). Least experienced auditors are more likely to make materiality judgments while performing detailed audit procedures but are not likely to have the experience to integrate a large amount of information to make appropriate judgments toward the end of the audit engagement. Thus, it is not likely that order effects will be mitigated in the least experienced auditor group. In contrast, the most experienced auditors have considerable knowledge integrating large amounts of information to make audit judgments with respect to the entire engagement. Thus, most experienced auditors are more likely to assess materiality with respect to the financial statements taken as a whole and would be more familiar with this study's task. Therefore, it is hypothesized that possible order effects will be mitigated for the most experienced auditor group. Finally, the experienced auditor group has a significant amount of recent audit procedural experience but also has a diverse range of experience reviewing audit working papers and, therefore, has some experience integrating large amounts of information for making judgments. It is hypothesized that order effects will not be mitigated in this group, but the magnitude of their revised materiality likelihood judgments will be less than those provided by the least experienced auditor group.

Therefore, hypothesis four, presented in three parts is as follows:

H4a: In the low (high) inherent risk audit environment the revised materiality likelihood judgments of least experienced auditors will exhibit significant primacy (recency) effects.

H4b: Regardless of the level of inherent risk the revised materiality likelihood judgments of most experienced auditors will not exhibit significant order effects.

H4c: In the low (high) inherent risk audit environment the revised materiality likelihood judgments of experienced auditors will exhibit significant primacy (recency) effects, and the magnitude of these judgments will be less than those of the least experienced auditors. 


\section{RESEARCH METHOD}

\section{Research Design}

The experiment consisted of a $2 \times 2 \times 3$ between-subjects design. The presentation order of information, the level of inherent risk in the auditing environment, and the level of experience were the three treatments considered. Presentation order was manipulated two ways. The first order required subjects to examine two, threeitem series of positive (confirming) qualitative information that would likely cause auditors to revise their initial materiality threshold upward followed by two, three-item series of negative (non-confirming) qualitative information that would likely cause auditors to not revise this threshold upward $(++--)$. The second presentation order is opposite that above $(--++)$. Inherent risk was manipulated two ways: high or low. The instrument required subjects to assess the level of inherent risk present in the audit environment. Finally, experience was a measured variable and consisted of the three experience groups as discussed above.

This design allowed for four instrument versions. Versions 1 and 2 contained the high inherent risk expectation with version 1 presenting the qualitative information in the confirming/non-confirming order $(++--)$ and version 2 reversing the qualitative information presentation $(--++)$. Versions 3 and 4 contained the low inherent risk expectation along with the qualitative information presentation orders as in versions 1 and 2 . The four instrument versions were randomly assigned equally within the specific experience groups by the expected high or low inherent risk assessment to assure the appropriate number usable responses.

\section{Experimental Task And Procedure}

The case instrument required auditor subjects to provide judgments regarding their willingness to revise their initial materiality threshold subsequent to the completion of audit fieldwork. To assure that the case materials reflect as realistic a setting as possible, the instrument was developed in conjunction with the participating firm's audit review partner. Subjects were pre-assigned to one of the four instruments versions as discussed above. To control and assure all subjects provided their judgments in a sequential, step-by-step fashion subjects completed the case instrument online. Participants accessed the case by logging into a designated web site with a unique login name and password, which directed them to the appropriate instrument. They could not proceed through the case without first responding to the judgment being asked. Attempting to do so would trigger an error message indicating that they may not continue until the current judgment is completed.

After successful login, subjects were directed to review the background information and financial statements of the fictitious audit client. Subjects then reviewed the client's inherent risk factors and assessed the level of inherent risk present in the audit environment. Case materials were designed to have auditors assess inherent risk as either high or low, but in practice, auditors may also assess this risk as medium. Therefore, a medium-level response option of inherent risk was incorporated into the case instrument. The effect of the mediumlevel response option is discussed in the results section.

Subsequent to documenting the inherent risk assessment, definitions of materiality were then presented along with the planning materiality calculation. Since the participating firm uses a standard planning materiality computation, providing this computation seemed warranted. However, each subject had the option of entering a unique planning materiality figure if he or she felt that the provided computation was deemed too high or too low. As expected, no subject changed the planning materiality figure. The consideration of internal control and the control risk assessment was presented next. The case materials indicated that the firm assessed the client's internal control as adequate, but no tests of controls would be performed. The firm would rely on substantive testing to form an adequate opinion of the financial statements. Subsequent to assessing control risk, participants were informed that the audit fieldwork had been completed and were asked to form a judgment on the materiality threshold for the client's income statement. This judgment represents the initial, post-fieldwork materiality threshold and provides the initial base from which further judgments on materiality were made. Subjects then reviewed the audit testing results and were to assume that the aggregate total of misstatements was two percent greater than their initial materiality threshold judgment just provided. 
Given this information, participants were asked if they would be willing to revise their initial materiality threshold upward. Specifically, the instrument asked the participants the following question, "Please document, between $0 \%$ and $100 \%$, the likelihood of revising your initial materiality threshold upward so that the aggregate total of the misstatements would be lower than the initial materiality threshold previously provided." This likelihood judgment represents the anchor judgment necessary to implement the Belief-Adjustment Model.

Subsequent to the documentation of the anchor judgment, subjects were provided with four, three-item series of additional qualitative information, which were based on the factors in SAB No. 99 and audit-firm factors identified through discussions with the audit review partner of the participating firm. After reading each three-item series, subjects were again asked to provide a likelihood judgment, between $0 \%$ and $100 \%$, about their willingness to revise their initial materiality threshold upward so that the revised threshold would be greater than the aggregate total of the misstatements, concluding that the misstatements were immaterial. As stated above, the qualitative factors were presented in two orders: two positive series of information followed by two negative series of information $(++--)$ or vice-versa $(--++)$. The decision about whether a factor listed in SAB No. 99 is positive or negative is based on the nature of the item and lengthy discussions with the general auditor partner of the participating firm. For those SAB No. 99 factors that were questionable, a number of audit scenarios and situations were discussed at length to assess whether a factor should be classified as positive or negative. Based on this discussion, it was determined that of the nine factors from SAB No. 99 considered for this study, six were deemed negative factors, while three were deemed positive factors. The remaining series of positive factors are based on the firm's relationship with the fictitious client. The six negative factors were grouped into two categories: weak negative and strong negative. Similarly, the positive factors were grouped as weak and strong, with the auditfirm/client relationship factors classified as weak positive and the three SAB No. 99 factors classified as strong positive. These classifications were determined based on discussions with the audit partner of the participating firm and the appropriateness of these categorizations is examined in the manipulation checks section that follows. Appendix A documents the specific qualitative factors used in this study.

Subsequent to documenting their likelihood revision judgments, after reviewing each series of qualitative information, participants were asked to complete factor importance ratings on each qualitative factor. The importance ratings allow the author to identify those SAB No. 99 factors and audit-firm factors that are most prevalent in the materiality revision decision. Finally, participants completed a personal information questionnaire.

\section{Participants}

Subjects were auditors from a Midwest regional CPA firm. The final usable sample includes 34 partners and managers (most-experienced group) with, on average, 18.6 years of experience, 20 supervisors and experienced senior auditors (experienced groups) with 8.2 years of experience, and 29 staff auditors (least-experienced group) averaging 2.3 years of experience. Task-specific experience, measured by the number of years each subject had in making materiality decisions, was 11.4 years for partners and managers, 3.4 years by the supervisors and experienced seniors, and 0.7 years by the staff auditors. A balanced number of instrument materials were distributed between each experience level. Table 1 shows the instrument dissemination characteristics by information presentation order and inherent risk, grouped by experience level.

\section{RESULTS}

\section{Manipulation Checks}

The instruments were manipulated by the level of inherent risk in the audit environment and by the presentation order of qualitative information. With respect to inherent risk, each respondent assessed the level of inherent risk present in the fictitious audit-client environment by responding as to whether inherent risk should be assessed as low, medium, or high. Of the initial 91 subjects who completed the case, two participants evaluated the high inherent risk information as low and two participants evaluated the low inherent risk information as high. As a result, these four participant responses were omitted from the sample due to their misunderstanding of the inherent risk assessment. 
Table 1

Instrument Dissemination Characteristics

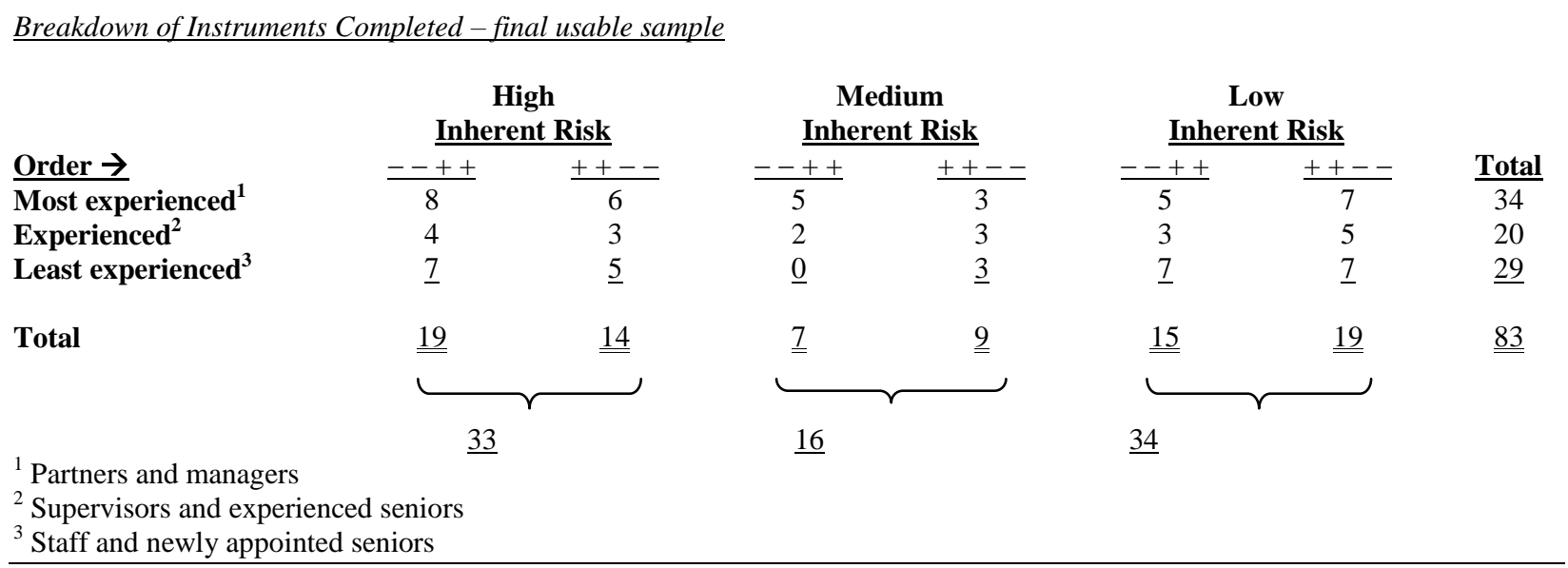

In addition, each subject was asked to complete four materiality revision judgment tasks after examining two, three-item series of positive information followed by two, three-item series of negative qualitative information, or vice versa. A review of the data revealed that four subjects did not understand the questions posed in the case. Specifically, these four subjects were more (less) willing to revise their materiality threshold upward after examining the negative (positive) factors - counterintuitive to the case materials. Consequently, these four participants they were also omitted, resulting in a final sample of 83 subjects.

As previously discussed, subjects were asked to complete factor importance ratings after making their revision judgments. These ratings were used to ascertain whether the factors identified as weakly and strongly negative and positive were considered as such by the participants. Subjects rated the strong negative factors as more important, on average, than the weak negative factors $(\mathrm{t}=3.78, \mathrm{p}<0.01)$. In addition, subjects rated the strong positive factors as more important than the weak positive factors $(\mathrm{t}=7.30, \mathrm{p}<0.01)$. Similar results obtain, when the factor importance ratings are separated into their order of presentation. The manipulation checks also revealed that the percentage change in the likelihood judgments is consistent with the level of factor importance. Overall, based on the above manipulation check analysis, the qualitative factors were properly classified.

\section{Hypotheses Tests}

Hypothesis one examines whether the initial likelihood judgments (the anchor judgment) of revising the initial materiality threshold in the low inherent risk audit environment will be greater than those in the high inherent risk audit environment. As shown in Table 1, a total of 34 subjects assessed the low inherent risk instruments as low and 33 subjects assessed the high inherent risk instruments as high. The remaining 16 subjects identified the inherent risk level as medium, a reasonable expectation in practice. Accordingly, these 16 subject responses were excluded from hypothesis one testing. The analysis reveals that the mean anchor judgment of 40.29 in the low inherent risk environment is significantly larger than the mean anchor judgment of 24.09 in the high inherent risk environment ( $\mathrm{t}=2.28, \mathrm{p}=0.026$, results not tabulated). This result indicates that subjects in the low (high) inherent risk audit environment are approximately 40 percent ( 24 percent) likely to revise the initial materiality judgment upward so that the revised materiality threshold would be greater than the aggregate total of the misstatements, concluding that the misstatements are quantitatively immaterial. This supports the contention that auditors who are presented with information in a higher risk audit environment will employ greater cognitive effort and make judgments using a heightened sense of professional skepticism when performing materiality judgment tasks. In addition, this also supports the contention that auditors who are making judgments in a low risk environment are not expecting to identify obvious errors or misstatements while planning and performing audit procedures, and that the 
level of professional skepticism employed in making materiality judgments may be relaxed. Thus, hypothesis one is supported.

Hypothesis two posits that the decision to revise the initial materiality threshold is a function of the interaction between the presentation order of information and the level of inherent risk present in the audit environment. Similar to Anderson and Maletta (1999), the dependent variable is a net revision score, computed by subtracting the anchor likelihood judgment from the final likelihood judgment (the fourth revised materiality likelihood judgment). The independent variables are the level of inherent risk as assessed by the subjects (high, medium or low) and the order of the qualitative information, either $(--++)$ or $(++--)$. Table 2 presents the ANOVA results, which indicate that the interaction between the level of inherent risk and information order is significant at a p-value $=0.0397$. Consistent with hypothesis two, the results in Table 2 show that the level of inherent risk present in audit environment and the order in which the qualitative factor information is presented is important to the auditor's willingness to revise the initial materiality likelihood judgment. Therefore, hypothesis two is supported.

Table 2

ANOVA Results for Auditors' Revision Judgments of Materiality By Inherent Risk and Presentation Order of Information

\begin{tabular}{|c|c|c|c|c|c|}
\hline Source of Variation & Df & $\underline{\text { Sum of Squares }}$ & $\underline{\text { Mean Square }}$ & F-Value & p-value \\
\hline $\begin{array}{l}\text { Main Effects: } \\
\text { Inherent Risk (IR) }\end{array}$ & 2 & 4950.67 & 2475.33 & 2.66 & 0.0763 \\
\hline Order & 1 & 2333.58 & 2333.58 & 2.51 & 0.1173 \\
\hline $\begin{array}{l}\text { Interaction: } \\
\text { IR x Order }\end{array}$ & 2 & 6257.65 & 3128.82 & 3.36 & 0.0397 \\
\hline
\end{tabular}

Anderson and Maletta (1999) found primacy effects when negative information preceded positive information in a low inherent risk setting and found that in a high inherent risk setting, order effects were mitigated or tended toward recency. A number of other audit studies have confirmed the recency effect in high-risk settings (Ashton and Ashton 1988; Tubbs et al. 1990; Asare 1992; Messier 1992; Reckers and Shultz 1993; Johnson 1995). When making judgments in high risk situations, auditors are more likely to raise their level of cognitive effort and are, therefore, more susceptible to recency effects. Therefore, hypothesis three tests whether in the low (high) inherent risk audit environment, auditors' revised materiality likelihood judgments result in a primacy (recency) effect.

For the low inherent risk audit environment, if the net revision score for the $(--++)$ order is more negative than the net revision score for the $(++--)$ order, then a primacy effect obtains. Figure 1, Panel A presents the mean auditor likelihood judgments of the subjects' willingness to revise the initial materiality threshold for the low inherent risk audit environment. The mean net revision score for the $(--++)$ information order is a positive $11.33(54.33-43.00)$, which is significantly greater than the mean net revision score for the $(++--)$ information order of $-5.37(\mathrm{t}=1.78, \mathrm{p}$-value $=0.0844)$. However, contrary to expectations, the resulting order effect is that of recency, not primacy, as is shown by the fishtail pattern in Figure 1, Panel A.

For the high inherent risk audit environment, the judgments are analyzed to determine if the expected positive mean net revision score for the $(--++)$ order is significantly greater than the expected negative mean net revision score for the $(++--)$ order. If so, then a recency effect obtains. As shown in Figure 1, Panel B, the resulting pattern indicates the expected recency effect. The mean net revision score for the $(--++)$ order is 28.00 , which is significantly greater than the mean net revision score for the $(++--)$ order of $-5.00(\mathrm{t}=4.05$, $\mathrm{p}$-value $=$ 0.0004). Given the above results, hypothesis three is partially supported. 
Figure 1

Mean Auditor Judgments of Auditors' Willingness to Revise the Initial Materiality Threshold by Inherent Risk and Order

\section{Panel A: Low Inherent Risk}

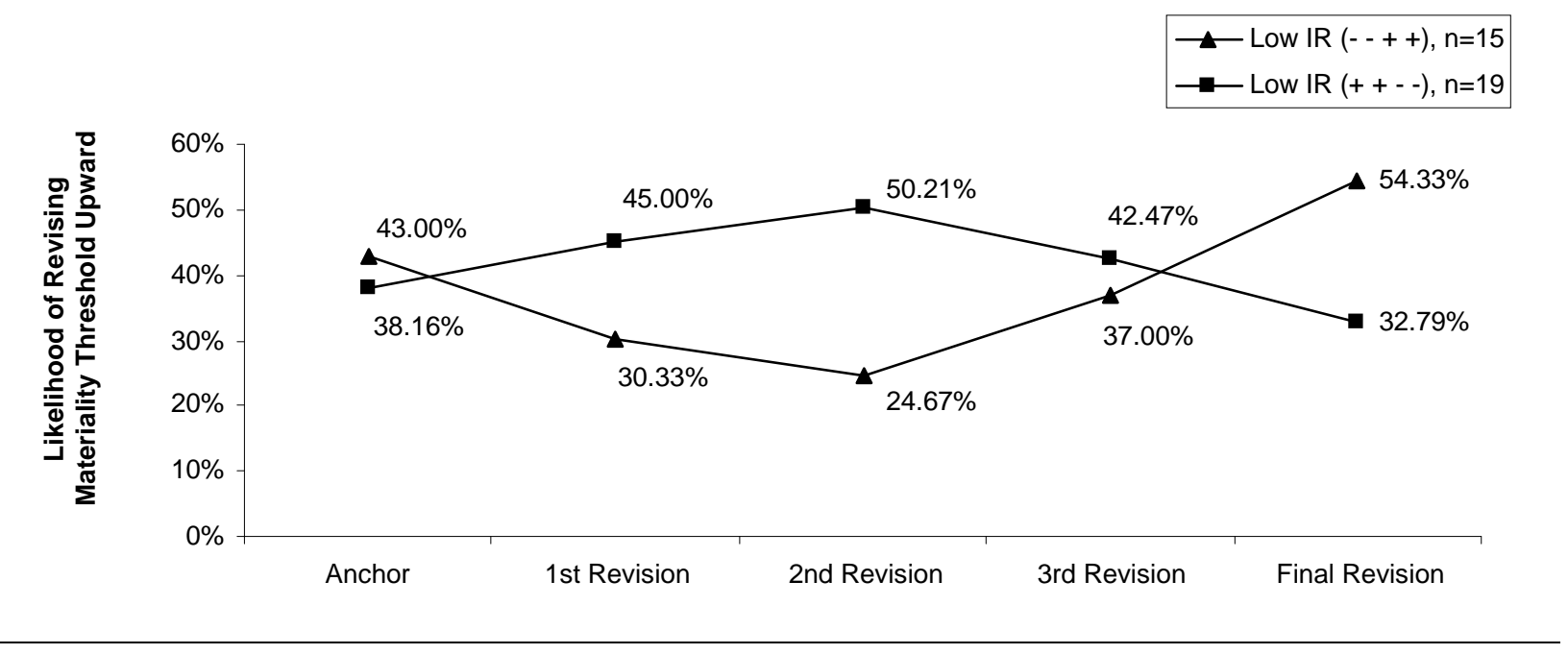

Panel B: High Inherent Risk

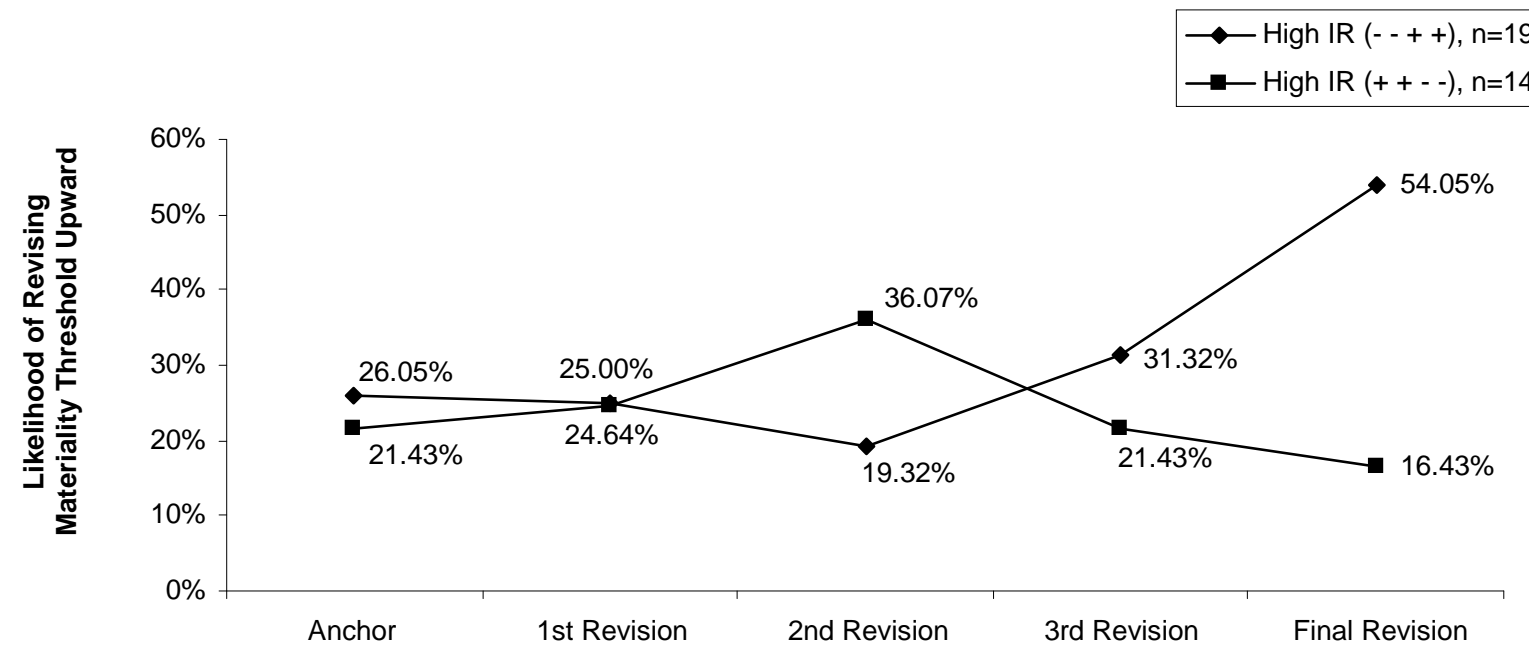

The results above for both levels of inherent risk show that recency effects are prevalent in the decision to revise the materiality threshold, meaning that no matter what the risk level, recency effects obtain. However, the significant interaction effect of hypothesis two indicates that both the level of inherent risk and presentation order are important to the revision decision. Further explanation is warranted. As noted above, 34 of the subjects that were provided with instruments with low inherent risk information correctly identified it as such. Similarly, 33 subjects that were provided instruments with high inherent risk information correctly identified it as such. The remaining 16 subjects identified the inherent risk level as medium, a reasonable expectation in practice. These 16 subject responses are included in the analysis of hypothesis two. To determine how the medium inherent risk responses influence the interaction test of hypothesis two additional analyses similar to that performed for hypothesis three is completed for the medium inherent risk responses. 
The results (not tabulated) indicate the mean net revision score for the $(--++)$ information order is -17.86 , whereas the mean net revision score for the $(++--)$ information is -2.22 . Although the $t$-test on the mean net revision scores is insignificant at a $\mathrm{p}$-value $=0.4813(\mathrm{t}=0.72)$, the resulting mean net revision scores tend toward primacy. More specifically, auditors failed to integrate the late positive information into their decision processes, resulting in more weight being placed on the negative information presented first. This result is similar to that found by Anderson and Maletta (1999). A nonparametric, Wilcoxon signed rank test is also performed on the difference between the net revisions scores and the result is insignificant.

In summary, the results for hypothesis three show that the presentation order of information is a significant determinant in auditors' willingness to revise the initial materiality threshold. In both the low and high inherent risk audit environments, a recency effect is present. In the medium inherent risk environment, the results tend toward primacy but are not significant. As such, hypothesis two and three are partially supported by the results.

Hypothesis four considers the presence or mitigation of order effects within each experience group. Auditors with the least amount of experience are expected to exhibit order effects in their materiality revision judgments, whereas the most experience auditors are not expected to exhibit any order effects. Experienced auditors are expected to exhibit order effects but the magnitude of those effects is not expected to be as pronounced as the least experienced auditor group. Non-parametric Wilcoxon ranks tests are computed on the net revision scores for each experience group by inherent risk and order. Non-parametric tests are utilized to test this hypothesis due to the relatively small sample sizes within each cell. Table 3 presents the treatment cell means of the net revision scores for each experience group by inherent risk and presentation order of information.

For the least experienced group, Table 3 shows that in the low inherent risk environment, the mean net revision score is 4.29 for the $(--++)$ order, and -3.14 for the $(++--)$ order. As hypothesized, these results tend toward recency but are not significant $(\mathrm{p}$-value $=0.3295)$. For the high inherent risk setting, the mean net revision score is 33.14 for the $(--++)$ order, and 1.00 for the $(++--)$ order. These results are significant (p-value $=$ 0.0102) and indicative of a recency effect. Therefore, in the high inherent risk audit environment, the revised materiality likelihood judgments of staff and newly appointed senior auditors do exhibit significant recency effects, as expected. As such, $\mathrm{H} 4 \mathrm{a}$ is partially supported.

Table 3

Auditors' Materiality Likelihood Judgments - Net Revision Scores Treatment Cell Means by Inherent Risk, Presentation Order and Experience Group

\begin{tabular}{|c|c|c|c|c|c|}
\hline \multirow[b]{2}{*}{$\begin{array}{l}\text { Presentation Order } \rightarrow \\
\text { Experience Level }^{1} \text { : }\end{array}$} & \multicolumn{2}{|c|}{$\underline{\text { LOW Inherent Risk }}$} & \multicolumn{2}{|c|}{ HIGH Inherent Risk } & \multirow[b]{2}{*}{$\underline{\text { Total }}$} \\
\hline & $\underline{(-++)}$ & $\underline{(++--)}$ & $\underline{(--++)}$ & $\underline{(++--)}$ & \\
\hline 1.) Least experienced & $\begin{array}{l}4.29 \\
(n=7)\end{array}$ & $\begin{array}{l}-3.14 \\
(n=7)\end{array}$ & $\begin{array}{l}33.14^{\mathrm{a}} \\
(\mathrm{n}=7)\end{array}$ & $\begin{array}{l}1.00^{a} \\
(n=5)\end{array}$ & $\begin{array}{c}9.42 \\
(n=26)\end{array}$ \\
\hline 2.) Experienced & $\begin{array}{l}10.00 \\
(n=3)\end{array}$ & $\begin{array}{l}-1.00 \\
(n=5)\end{array}$ & $\begin{array}{l}33.75 \\
(n=4)\end{array}$ & $\begin{array}{l}-3.33 \\
(n=3)\end{array}$ & $\begin{array}{c}10.00 \\
(n=15)\end{array}$ \\
\hline 3.) Most experienced & $\begin{array}{l}22.00^{b} \\
(n=5)\end{array}$ & $\begin{array}{c}-10.71^{b} \\
(n=7)\end{array}$ & $\begin{array}{l}20.63^{c} \\
(n=8)\end{array}$ & $\begin{array}{r}-10.83^{c} \\
(n=6)\end{array}$ & $\begin{array}{c}5.20 \\
(n=26)\end{array}$ \\
\hline TOTALS & $\begin{array}{c}11.34 \\
(n=15)\end{array}$ & $\begin{array}{c}-5.37 \\
(n=19)\end{array}$ & $\begin{array}{c}28.00 \\
(n=19)\end{array}$ & $\begin{array}{c}-5.00 \\
(n=14)\end{array}$ & $\begin{array}{c}7.91 \\
(n=67)\end{array}$ \\
\hline
\end{tabular}

Wilcoxon two-sample test: $\quad \mathrm{a}=$ significant at the .01 level

$\mathrm{b}=$ significant at the .05 level

$\mathrm{c}=$ significant at the .10 level

Note: The usable sample totals 83 subjects, of which, 16 subjects assessed inherent risk as medium. These subject responses are not included in the above analysis due to the medium inherent risk assessment is not hypothesized in this study.

${ }^{1}$ Least experienced auditors are staff and newly appointed seniors, experienced auditors are experienced seniors and supervisors, and most experienced auditors are managers and partners. 
The most experienced auditors are not expected to exhibit any order effects. As shown at Table 3 for the low inherent risk environment, the mean net revision score is 22.00 for the $(--++)$ order, and -10.71 for the $(++--)$ order. These results are significant (p-value 0.0380) and indicate a recency effect. Similarly for the high inherent risk audit environment, the mean net revision score is 20.63 for the $(--++)$ order, and -10.83 for the $(++$ $--)$ order. These results also reflect a recency effect and are significant at a p-value of 0.0609 . The results show that no matter what the assessed level of inherent risk, the most experienced auditors are susceptible to order effects, specifically recency effects, when making decisions about whether to revise the post-fieldwork materiality threshold.

These results are contrary to the expectations of hypothesis $4 \mathrm{~b}$ and are analogous to Arnold et al. (2000), who examined the effects of experience and task complexity on order and recency bias in auditor decision making. Arnold et al. (2000) specifically incorporated both information load and task familiarity into their two experiments to test whether experience mitigates order effects. They found that when information load remained high, even when the task was familiar to the participants, experience did not mitigate recency effects among more experienced auditors. In fact, more-experienced auditors exhibited greater levels of bias than did lesser-experienced auditors. Krull et al. (1993) found similar results and proposed that sequential processing of information was not as common for more experienced auditors, and thus, the response mode may have forced the extreme order effects of experienced auditors.

Finally, for the experienced auditor group, Table 3 shows for the low inherent risk environment, a mean net revision score of 10.00 for the $(--++)$ order, and -1.00 for the $(++--)$ order. Consistent with results found for the other two experience groups, the results tend towards recency and not primacy, but are not significant ( $\mathrm{p}$-value $=$ 0.2389). For the high inherent risk audit environment, the mean net revision score is 33.75 for the $(--++)$ order, and -3.33 for the $(++--)$ order. As expected, the results indicate a recency effect, but are not significant (p-value $=0.1628$ ). In addition, comparison tests ${ }^{4}$ on the magnitude of recency effects indicate no significant differences between the mean net revision scores of the least experienced group and the experienced auditor group. The results achieved tend toward the expectations of hypothesis $4 \mathrm{c}$ but are not significant.

\section{SUMMARY AND DISCUSSION}

Overall, the results of this study have significant implications for auditing practitioners and policy makers. As noted above, the results identified a number of qualitative factors that auditors considered important when making a revision choice on the initial materiality threshold. In addition, auditors did in fact use this qualitative information when making subsequent revisions. These results should provide the SEC with some initial comfort that auditors do consider qualitative information when making materiality revision judgments. The auditor subjects were also able to identify which qualitative factors were weakly and strongly negative and positive. In addition, most auditors were able to appropriately identify the proper level of inherent risk present in the fictitious audit client environment; the initial anchor likelihood judgments reflected this.

What is troubling from a practitioner perspective is the resulting order effect bias. Regardless of whether the inherent risk level was low or high, significant recency effects obtain. This result may have serious implications as to the cost and quality of current audit engagements, as suggested by Ashton and Ashton (1988). The willingness to revise the initial post-fieldwork materiality threshold was directly affected by the order in which the qualitative factor information was presented. More specifically, when the qualitative information was presented in the (++- -) order, auditors were less willing to revise the initial materiality threshold. On the other hand, when the qualitative information was presented in the $(--++)$ order, auditors were significantly more likely to revise this threshold.

In addition to the potential impact on the cost and quality of audits, these results suggest that auditors may be exposing themselves to heightened levels of financial reporting risk. This is especially the case given a $(--++)$ information presentation order. The results suggest that auditors are more than 50 percent willing to revise the initial materiality threshold upward so that seemingly material misstatements become quantitatively immaterial to

\footnotetext{
${ }^{4}$ Wilcoxon ranks tests were performed on the net revision scores between the least experienced auditor group and the experienced auditor group for each presentation order and inherent risk level.
} 
the audit engagement. Thus, the misstatements would likely not be booked as audit adjustments by the client management, even though the misstatements may be material in a qualitative context. These are situations that the SEC is concerned about and senses that corporations may be booking or waiving adjustments to meet analysts' forecasted earnings per share numbers in order to achieve possible management bonus thresholds, to avoid the possibility of violating loan covenants or contractual obligations, or to avoid losing market value.

The results also indicated that the order effect bias was not mitigated by experience level. In fact, the results showed that the identified recency effects were exacerbated in the most experienced auditor group. Across both levels of inherent risk, the most experienced auditors exhibited the most pronounced recency effects. This is of major concern considering it is this group that has the final say as to whether the initial materiality threshold should be revised.

Based on these findings, the concerns of the SEC seem warranted. Although auditors are using qualitative information to make decisions regarding materiality and are willing to revise materiality thresholds, these judgments are significantly influenced by the order in which this qualitative information enters into the decision process. If the information enters into the auditors' decision processes by the $(--++)$ order, then it appears that the financial reporting risk of auditors is heightened by the impact of order effects on materiality revision judgments.

This study has a number of limitations. First, the data were gathered using only one firm so the sample size is limited. A second limitation is the presentation of the seemingly material misstatements in the experimental task. The case instrument presented the material misstatements as totaling two percent more than the initial materiality threshold. In an actual audit engagement, auditors would know specifically what types of misstatements were identified, which accounts would be affected, and the amounts in question. Having specific information on the actual misstatements would provide auditors with a better understanding as to which misstatements are potentially material and which ones are immaterial. However, implementing specific audit adjustments into the instruments would have been very difficult, especially since each participant was asked to provide his or her own initial materiality threshold. It is highly likely that the aggregate total of specific audit adjustments would have been significantly greater than some of the subjects' initial threshold, thus causing these subjects to consider not revising at all. On the other hand, it is also highly likely that the aggregate total of specific audit adjustments would have been significantly smaller than some of the subjects' initial thresholds, therefore initially creating quantitatively immaterial audit adjustments. A third limitation is the response mode utilized in this study. In practice, auditors are likely to make judgments using a combination of step-by-step and end-of-sequence response modes.

Future research could expand the sample size to "Big 4" accounting firms. This extension would allow for cross-firm comparisons and would assist in generalizing the results. In addition, this type of large firm $/ \mathrm{small}$ firm comparison would help to determine if different qualitative factors are considered important to auditors who are employed at different sized firms. Other materiality judgment contexts could be analyzed to determine if qualitative information would be utilized. For example, specific misstatements that are quantitatively immaterial could be presented within the case instrument, and auditor subjects could be asked to assess whether the misstatement should be booked given the qualitative information presented in this study. Finally, the integration of a dual response mode study could be implemented. Subjects could be assigned to two specific groups: those who would respond using a step-by-step response mode, and those who would respond using an end-of-sequence response mode. This instrument implementation would allow for cross comparisons between response modes to determine if the end-ofsequence response mode would mitigate order effects. 


\section{APPENDIX A}

\section{Qualitative Factors Examined By Study Participants}

Weak Negative Qualitative Factor Items (from SAB No. 99)

(1) Possible violation of contractual obligations and agreements if the misstatements are determined to be material,

(2) The reversal of a five-year earnings trend if the misstatements are determined to be material, and

(3) The reversal of earnings from positive to negative in a subsidiary product line if the misstatements are determined to be material.

Strong Negative Qualitative Factor Items (from SAB No. 99)

(1) Possible violation of regulatory requirements if the misstatements are determined to be material.

(2) Possible violation of debt covenants if the misstatements are determined to be material.

(3) Elimination of management bonus compensation if the misstatements are determined to be material.

Weak Positive Qualitative Factor Items (auditor/client relationship factors)

(1) The firm's willingness to waive similar types of misstatements in past audit years, and the possibility of the client seeking new auditors in the future if "forced" to book the misstatements in the current year.

(2) The revenues provided from the engagement are significant to the firm's total revenues, and if the client is lost, then possible layoffs of firm personnel are likely.

(3) The fact that all previous audit opinions issued by the firm for this client have been unqualified.

Strong Positive Qualitative Factor Items (from SAB No. 99)

(1) The nature of the misstatements is a combination of projected misstatements and known misstatements. The projected misstatements are classified as predominantly income reducing while the known misstatements are classified as predominantly income increasing. This combination reflects the imprecision inherent in the aggregate misstatement amount.

(2) Each individual misstatement is immaterial, or below the initial materiality threshold, but in the aggregate, the total amount of the misstatements is material, or 2 percent above the initial materiality threshold.

(3) The misstatements do not appear to be related to any possible fraudulent activity by management or hourly personnel.

\section{AUTHOR INFORMATION}

Charles A. Brown, $\mathrm{PhD}, \mathrm{CPA}$, is an associate professor of accounting in the Sam and Irene Black School of Business at Penn State Erie, The Behrend College. His current research focuses on auditor decision making, market-based prediction and forecasting, as well as applied managerial/cost accounting studies. His work has been published in academic and practitioner journals and presented at academic conferences. He has had previous auditing experience with a regional CPA firm in Ohio auditing real estate developers, steel fabrication companies, thoroughbred horse racing tracks, and non-for-profit organizations.

\section{REFERENCES}

1. Ahlawat, S. S. (1999). Order effects and memory for evidence in individual versus group decision making in auditing. Journal of Behavioral Decision Making, 12 (March), 71-88.

2. American Institute of Certified Public Accountants (AICPA). (2001). AICPA Professional Standards, Vol. 1. New York: AICPA, Inc. 
3. Anderson, B. H., and Maletta, M. J. (1999). Primacy effects and the role of risk in auditor belief-revision processes. AUDITING: A Journal of Practice \& Theory, 18 (Spring), 75-89.

4. Anderson, N. H. (1981). Foundations of information integration theory. New York: Academic Press, Inc.

5. Anderson, N. H., and Hubert, S. (1963). Effects of concomitant verbal recall on order effects in personality impression formation. Journal of Verbal Learning and Verbal Behavior, 2, 379-391.

6. Arnold, V., Collier, P. A., Leech, S. A., and Sutton, S. G. (2000). The effect of experience and complexity on order and recency bias in decision making by professional accountants. Accounting and Finance, 40 (July), 109-134.

7. Asare, S. K. (1992). The auditor's going-concern decision: Interaction of task variables and the sequential processing of evidence. The Accounting Review, 67 (April), 379-393.

8. Ashton, A. H., and R. H. Ashton. (1988). Sequential belief revision in auditing. The Accounting Review, 63 (October), 623-641.

9. Ashton, R. H., and Kennedy, J. (2002). Eliminating recency with self-review: The case of auditors' going concern judgments. Journal of Behavioral Decision Making, 15 (July), 221-231.

10. Boatsman, J. R., and Robertson, J. C. (1974). Policy-capturing on selected materiality judgments. The Accounting Review, 49 (April), 342-352.

11. Braun, K. W. (2001). The disposition of audit-detected misstatements: An examination of risk and reward factors and aggregation effects. Contemporary Accounting Research, 18 (Spring), 71-99.

12. Chewning, G., Pany, K., and Wheeler, S. (1989). Auditor reporting decisions involving accounting principle changes: Some evidence on materiality thresholds. Journal of Accounting Research, 27 (Spring), 78-96.

13. Chewning, G., Wheeler, S., and Chan, K. (1998). Evidence on auditor and investor materiality thresholds resulting from equity-for-debt swaps. AUDITING: A Journal of Practice \& Theory, 17 (Spring), 39-53.

14. Cushing, B. E., and Ahlawat, S. S. (1996). Mitigation of recency bias in audit judgment: The effect of documentation. AUDITING: A Journal of Practice \& Theory, 15 (Fall), 110-122.

15. Dillard, J. F., Kauffman, N. L., and Spires, E. E. (1991). Evidence order and belief revision in management accounting decisions. Accounting, Organizations and Society, 16 (7), 619-633.

16. Favere-Marchesi, M. (2006). "Order effects" revisited: The importance of chronology. Auditing: A Journal of Practice and Theory, 25 (1), 69-83.

17. Friedberg, A. H., Strawser, J. R., and Cassidy, J. H. (1989). Factors affecting materiality judgments: A comparison of big eight accounting firms materiality views with the results of empirical research. In B. N. Schwartz (ed.), Advances in Accounting, 7, (187-201). Greenwich, CT: JAI Press, Inc.

18. Guiral-Contreras, A., Gonzalo-Angulo, J. A., and Rodgers, W. (2007). Information content and recency effect of the audit report in loan rating decisions. Accounting and Finance, 47 (2), 285-304.

19. Hendrick, C., and Costantini, A. F. (1970). Effects of varying trait inconsistency and response requirements on the primacy effect in impression formation. Journal of Personality and Social Psychology, 15 (2), 158-164.

20. Hogarth, R. M., and Einhorn, H. J. (1992). Order effects in belief updating: The belief-adjustment model. Cognitive Psychology, 24, 1-55.

21. Holstrum, G. L., and Messier, W. F., Jr. (1982). A review and integration of empirical research on materiality. Auditing: A Journal of Practice and Theory, 2 (Fall), 45-63.

22. Hunton, J. E. (2001). Mitigating the common information sampling bias inherent in small-group discussion. Behavioral Research in Accounting, 13, 171-193.

23. Jennings, M., Kneer, D., and Reckers, P. (1987). A reexamination of the concept of materiality: Views of auditors, users, and officers of the court. AUDITING: A Journal of Practice \& Theory, 6 (Spring), 104115 .

24. Johnson, E. N. (1995). Effects of information order, group assistance, and experience on auditors' sequential belief revision. Journal of Economic Psychology, 16 (March), 137-160.

25. Kennedy, J. (1993). Debiasing audit judgment with accountability: A framework and experimental results. Journal of Accounting Research, 31 (Autumn), 231-245.

26. Krogstad, J. L., Ettenson, R. T., and Shanteau, J. (1984). Context and experience in auditors' materiality judgments. AUDITING: A Journal of Practice \& Theory, 4 (Fall), 54-73. 
27. Krull, G., Jr., Reckers, P. M. J., and Wong-on-Wing, B. (1993). The effect of experience, fraudulent signals and information presentation order on auditors' beliefs. AUDITING: A Journal of Practice \& Theory, 12 (Fall), 143-153.

28. Marsh, T. L. (1997). An empirical examination of materiality by factor analysis and cognitive mapping of user and preparer groups. Dissertation Abstracts International, 58 (03), p. 970 (Publication No. AAT9727022).

29. Messier, W. F., Jr. (1983). The effect of experience and firm type on materiality/ disclosure judgments. Journal of Accounting Research, 21 (Autumn), 611-618.

30. Messier, W. F., Jr. (1992). The sequencing of audit evidence: Its impact on the extent of audit testing and report formulation. Accounting and Business Research, 22 (Spring), 143-150.

31. Messier, W. F., Jr., and Tubbs, R. M. (1994). Recency effects in belief revision: The impact of audit experience and the review process. AUDITING: A Journal of Practice \& Theory, 13 (Spring), 57-72.

32. Monroe, G. S., and Ng, J. (2000). An examination of order effects in auditors' inherent risk assessments. Accounting and Finance, 40 (2), 153-168.

33. Moriarity, S., and Barron, F. H. (1979). A judgment-based definition of materiality. Journal of Accounting Research, 17 (supplement), 114-135.

34. Pany, K., and Wheeler, S. (1989). Materiality: An inter-industry comparison of the magnitudes and stabilities of various quantitative measures. Accounting Horizons, 3 (December), 71-78.

35. Pattillo, J. W. (1976). The concept of materiality in financial reporting. New York, NY: Financial Executives Research Foundation.

36. Pei, B. K. W., Reckers, P. M. J., and Wyndelts, R. W. (1992a). Tax professionals belief revision: The effects of information presentation sequence, client preference, and domain experience. Decision Sciences, 23 (January/February), 175-199.

37. Pei, B. K. W., Reed, S. A., and Koch, B. S. (1992b). Auditor belief revisions in a performance auditing setting: An application of the belief-adjustment model. Accounting, Organizations and Society, 17 (2), 169-183.

38. Reckers, P. M. J., and Schultz, J. J., Jr. (1993). The effects of fraud signals, evidence order, and groupassisted counsel on independent auditor judgment. Behavioral Research in Accounting, 5, 124-144.

39. Securities and Exchange Commission (SEC). (1999). SEC Staff Accounting Bulletin: No. 99 - Materiality. Washington, DC: SEC.

40. Slipp, J. (1983). Materiality: A practitioner's dilemma. CA Magazine, 116 (January), 62-63.

41. Steinbart, P. J. (1987). The construction of a rule-based expert system as a method for studying materiality judgments. The Accounting Review, 62 (January), 96-116.

42. Trotman, K. T., and Wright, A. (1996). Recency effects: Task complexity, decision mode, and taskspecific experience. Behavioral Research in Accounting, 8, 175-193.

43. Tubbs, R. M., Messier, W. F., Jr., and Knechel, W. R. (1990). Recency effects in the auditor's beliefrevision process. The Accounting Review, 65 (April), 452-460.

44. Tuttle, B., Coller, M., and Burton, F. G. (1997). An examination of market efficiency: Information order effects in a laboratory market. Accounting, Organizations and Society, 22 (1), 89-103.

45. Walker, R. H. (1999). In quotes: The SEC director of enforcement addresses the importance of being independent. Auditor independence: The issues. The CPA Journal, 69 (5), 44-50.

46. Waters, J. M., II, and Tiller, M. G. (1997). Auditors' materiality thresholds: Some empirical findings based on real data. American Business Review, 15 (June), 115-119.

47. Wheeler, S., Pany, K., and Chewning, E. (1993). Inter-firm differences in propensities to modify audit opinions for pre-SAS No. 58 accounting principle changes. Accounting Horizons, 7 (September), 46-54.

48. Wright, A., and Wright, S. (1997). An examination of factors affecting the decision to waive audit adjustments. Journal of Accounting, Auditing \& Finance, 12 (Winter), 15-36. 
NOTES 